\title{
ON APPROXIMATING THE ERROR FUNCTION
}

\section{Zhen-Hang Yang, Wei-Mao Qian, Yu-Ming Chu and Wen Zhang}

Abstract. In the article, we find the best possible parameters $p$ and $q$ on the interval $(7 / 5,(7 \pi-$ $20) /(5 \pi-15))$ such that the double inequality

$$
\sqrt{1-\lambda(p) e^{-p x^{2}}-(1-\lambda(p)) e^{-\mu(p) x^{2}}}<\operatorname{erf}(x)<\sqrt{1-\lambda(q) e^{-q x^{2}}-(1-\lambda(q)) e^{-\mu(q) x^{2}}}
$$

holds for all $x>0$, where $\operatorname{erf}(x)=\frac{2}{\sqrt{\pi}} \int_{0}^{x} e^{-t^{2}} d t$ is the error function, $\lambda(p)=4[(7 \pi-20)-$ $5(\pi-3) p] /\left[\pi\left(15 p^{2}-40 p+28\right)\right], \mu(p)=4(5 p-7) /[5(3 p-4)]$.

Mathematics subject classification (2010): 33B20, 26D15, 26A48.

Keywords and phrases: error function, gamma function, monotonicity, bound.

\section{REFERENCES}

[1] K. M. AludaAt And M. T. Alodat, A note on approximating the normal distribution function, Appl. Math. Sci. 2, 9-12 (2008), 425-429.

[2] H. Alzer, On some inequalities for the incomplete gamma function, Math. Comp. 66, 218 (1997), $771-778$

[3] H. AlzER, Functional inequalities for the error function, Aequationes Math. 66, 1-2 (2003), 119-127.

[4] H. AlzER, Functional inequalities for the error function II, Aequationes Math. 78, 1-2 (2009), 113121.

[5] H. Alzer, Error function inequalities, Adv. Comput. Math. 33, 3 (2010), 349-379.

[6] A. V. BoYD, Inequalities for Mills' ratio, Rep. Statist. Appl. Res. Un. Jap. Sci. Engrs. 6 1959, 44-46.

[7] J. T. CHU, On bounds for the normal integral, Biometrika 42 1955, 263-265.

[8] Y.-M. ChU, M. Adil Khan, T. Ali And S. S. Dragomir, Inequalities for $\alpha$-fractional differentiable functions, J. Inequal. Appl. 2017 2017, Article 93, 12 pages.

[9] Y.-M. CHU, Y.-M. LI AND W.-F. XIA, Best possible inequalities for the harmonic mean of error function, J. Inequal. Appl. 2014 2014, Article 525, 9 pages.

[10] Y.-M. CHU, Y.-F. QIU AND M.-K. WANG, Hölder mean inequalities for the complete elliptic integrals, Integral Transforms Spec. Funct. 23, 7 (2012), 521-527.

[11] Y.-M. ChU And M.-K. WAng, Optimal Lehmer mean bounds for the Toader mean, Results Math. 61, 3-4 (2012), 223-229.

[12] Y.-M. ChU, M.-K. WANG, S.-L. QIU AND Y.-P. JiAng, Bounds for complete elliptic integrals of the second kind with applications, Comput. Math. Appl. 63, 7 (2012), 1177-1184.

[13] Y.-M. ChU, G.-D. WANG AND X.-H. ZhAng, Schur convexity and Hadamard's inequality, Math. Inequal. Appl. 13, 4 (2010), 725-731.

[14] Y.-M. CHU, G.-D. WANG AND X.-H. ZHANG, The schur multiplicative and harmonic convexities of the complete symmetric function, Math. Nachr. 284, 5-6 (2011), 653-663.

[15] Y.-M. ChU, W.-F. XIA AND X.-H. ZHANG, The Schur concavity, Shur multiplicative and harmonic convexities of the second dual form of the Hamy symmetric function with applications, J. Multivariate Anal. 105 2012, 412-421.

[16] Y.-M. ChU, X.-H. Zhang And G.-D. WANG, The Schur geometrical convexity of the extended mean values, J. Convex Anal. 15, 4 (2008), 725-731.

[17] Y.-M. ChU AND T.-H. ZhaO, Concavity of the error function with respect to Hölder means, Math. Inequal. Appl. 19, 2 (2016), 589-595.

[18] W. J. CoDY, Rational Chebyshev approximations for the error function, Math. Comp. 23 1969, 631637. 
[19] A. Gasull And F. Utzet, Approximating Mills ratio, J. Math. Anal. Appl. 420, 2 (2014), 1832 1853.

[20] W. GAUTSCHI, Some elementary inequalities relating to the gamma and incomplete gamma function, J. Math. Phys. 38 1959/60, 77-81.

[21] R. G. HART, A close approximation related to the error function, Math. Comp. 20 1966, 600-602.

[22] A. LAFOrgia AND S. SiSmONDI, Monotonicity results and inequalities for the gamma and error functions, J. Comput. Appl. Math. 23, 1 (1988), 25-33.

[23] Y.-M. LI, W.-F. XIA, Y.-M. ChU AND X.-H. ZHANG, Optimal lower and upper bounds for the geometric convex combination of the error function, J. Inequal. Appl. 2015 2015, Article 382, 8 pages.

[24] E. Neuman, Inequalities and bounds for the incomplete gamma function, Results Math. 63, 3-4 (2013), 1209-1214.

[25] G. PóLYA, Remarks on computing the probability integral in one and two dimensions, Proceedings of the Berkeley Symposium on Mathematical Statistics and Probability, University of California Press, Berkely and Los Angeles, 1949.

[26] M.-K. WANG AND Y.-M. ChU, Asymptotical bounds for complete elliptic integrals of the second kind, J. Math. Anal. Appl. 402, 1 (2013), 119-126.

[27] M.-K. WANG AND Y.-M. CHU, Refinements of transformation inequalities for zero-balanced hypergeometric functions, Acta Math. Sci. 37B, 3 (2017), 607-622.

[28] M.-K. WANG, Y.-M. ChU AND Y.-P. JiAng, Ramanujan's cubic transformation inequalities for zero-balanced hypergeometric functions, Rocky Mountain J. Math. 46, 2 (2016), 679-691.

[29] M.-K. WANG, Y.-M. CHU AND S.-L. QIU, Asymptotical formulas for Gaussian and generalized hypergeometric functions, Appl. Math. Comput. 276 2016, 44-60.

[30] M.-K. WANG, Y.-M. ChU, S.-L. QIU AND Y.-P. JIANG, Bounds for the perimeter of an ellipse, J. Approx. Theory 164, 7 (2012), 928-937.

[31] M.-K. WANG, Y.-M. ChU, Y.-F. QIU AND S.-L. QIU, An optimal power mean inequality for the complete elliptic integrals, Appl. Math. Lett. 24, 6 (2011), 887-890.

[32] M.-K. WANG, Y.-M. LI AND Y.-M. CHU, Inequalities and infinite product formula for Ramanujan generalized modular equation function, Ramanujan J. doi : 10.1007/s11139-017-9888-3.

[33] M.-K. WANG, S.-L. QIU, Y.-M. ChU AND Y.-P. JiAng, Generalized Hersch-Pfluger distortion function and complete elliptic integrals, J. Math. Anal. Appl. 385, 1 (2012), 221-229.

[34] G.-D. WANG, X.-H. ZHANG AND Y.-M. CHU, Inequalities for the generalized elliptic integrals and modular functions, J. Math. Anal. Appl. 331, 2 (2007), 1275-1283.

[35] W.-F. Xia AND Y.-M. ChU, Optimal inequalities for the convex combination of error function, J. Math. Inequal. 9, 1 (2015), 85-99.

[36] Z.-H. YANG AND Y.-M. CHu, On approximating Mills ratio, J. Inequal. Appl. 2015 2015, Article 273, 14 pages.

[37] Z.-H. YANG AND Y.-M. ChU, On approximating the error function, J. Inequal. Appl. 2016 2016, Article 311, 17 pages.

[38] Z.-H. YANG AND Y.-M. CHU, A monotonicity property involving the generalized elliptic integral of the first kind, Math. Inequal. Appl. 20, 3 (2017), 729-735.

[39] Z.-H. YANG, Y.-M. CHU AND X.-J. TAO, A double inequality for the trigamma function and its applications, Abstr. Appl. Anal. 2014 2014, Article ID 702718, 9 pages.

[40] Z.-H. YANG, Y.-M. CHU AND M.-K. WANG, Monotonicity criterion for the quotient of power series with applications, J. Math. Anal. Appl. 428, 1 (2015), 587-604.

[41] Z.-H. YANG, W.-M. QIAN, Y.-M. ChU AND W. ZHANG, Monotonicity rule for the quotient of two functions and its application, J. Inequal. Appl. 2017 2017, Article 106, 13 pages.

[42] Z.-H. YANG, W.-M. QIAN, Y.-M. ChU AND W. ZHANG, On rational bounds for the gamma function, J. Inequal. Appl. 2017 2017, Article 210, 17 pages.

[43] Z.-H. YANG, W. ZhANG AND Y.-M. ChU, Sharp Gautsch inequality for parameter $0<p<1$, Math. Inequal. Appl. 20, 4 (2017), 1107-1120.

[44] X.-H. Zhang, G.-D. Wang And Y.-M. Chu, Remarks on generalized elliptic integrals, Proc. Roy. Edinburgh, Sect. A 139, 2 (2009), 417-426.

[45] X.-H. Zhang, G.-D. WANG AND Y.-M. ChU, Convexity with respect to Hölder mean involving zero-balanced hypergeometric functions, J. Math. Anal. Appl. 353, 1 (2009), 256-259. 